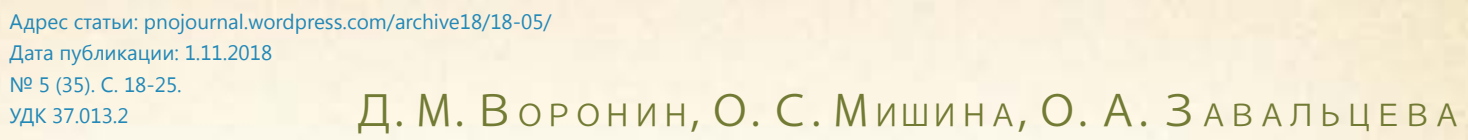

Исследование состояло из нескольких основных частей. На первом этапе был проведен анализ наиболее значимых глобальных трендов в мировом сообществе. Второй этап работы предусматривал анализ наиболее авторитетных международных рейтингов университетов и работу с основными параметрами рейтингования эффективности работы университета. Также были рассмотрены внешние и внутренние факторы, которые влияют на эффективность работы университета. Наибольшее внимание было уделено следующим внутренним факторам: стратегические ориентиры в отношении образовательных услуг, имеющиеся у вуза ресурсы и компетенции, характеристики предлагаемых образовательных услуг и стратегии их продвижения. Также в ходе работы был проведен анализ российских потребительских трендов. Работа посвящена формированию стратегии повышения качества образования в образовательных организациях на базе использования глобальных и развивающихся трендов, которые приводят к изменению ценностных ориентиров, влекут смещение акцентов заинтересованности потребителя и соответственно меняют показатели качества образования. В своей работе мы рассматриваем ключевые компетенции вузов и выпускников вузов, как основополагающий элемент конкурентоспособности университета.

Ключевые слова: качество образования, тренды, ключевые компетенции, компетенции выпускников, стратегия, эффективность, рейтинг quality evaluation and quality enhancement basics

The research has been made of several basic parts. At the first stage the analysis of the most significant global trends in the world community has been done. The second stage has involved the analysis of the most established international university ranks and observations into university effectiveness basic ranking parameters. The external and internal factors, having impact on university work effectiveness, have also been considered. Utmost attention has been paid to the following internal factors: strategical directions in relation to educational services, already existing university resources and competences, educational services provisional characteristics and their promotional strategies. Also the analysis of Russian consumer trends has been done through the course of work. The work is dedicated to education quality enhancement strategy forming based on global and developing trends implementation that lead to changes in values, result in consumer interest shift of emphasis and, accordingly, to alterations in education quality indicators. In our work we consider university and university graduates key competences as university competitive ability key basics.

Key words: Education quality, trends, key competences, graduates competences, strategy, effectiveness, rank 
ганизации, академическая информация, коммуникационные возможности; репутационное ранжирование (учитываются глобальные и национальные рейтинги, данные экспертного опроса)

$1 /$ онятие глобального тренда не является абсолютно новым, первые серьезные работы, посвященные данной проблематике, появились в 2005-2007 годах [1]. Именно для Российской Федерации является характерным видоизменение данных трендов в сравнении с их общемировыми проявлениями [2; 3]. Кроме трендов громадное влияние на структуру и содержание высшего образования имеют всемирные рейтинги эффективности работы университетов.

Для объективной оценки эффективности работы высших учебных заведений используют различные рейтинговые системы. Отметим ведущие критерии оценки эффективности по различным рейтингам.

QS World University Rankings использует следующие критерии: академическая репутация, репутация работодателей, соотношение преподавательского состава к количеству студентов, цитируемость научных публикаций, доля иностранных студентов, доля иностранных преподавателей [20].

The Times High Education World University Rankings также оценивает академическую репутацию, репутацию у работодателей, соотношение между обучающимися и преподавателями, долю иностранных преподавателей, но публикационная активность оценивается только по изданиям входящим в наукометрическую базу Scopus.

Academic Ranking of World Universities: научные публикации (количество публикаций и цитирований), качество преподавательского состава (наличие престижных научных премий и цитируемость преподавателей), качество обучения (количество выпускников получивших престижные научные премии) и академическая производительность (соотношение всех вышеуказанных показателей к численности персонала университета) [15].

Ranking Web of Universities рассматривает влияние (число уникальных внешних ссылок на сайт университета), присутствие (число страниц на сайте университета, проиндексированных поисковой системой Google), открытость (число файлов в формате pdf, doc/docx, ppt/pptx, eps/ ps на сайте университета по данным поисковой системы Google), превосходство (доля статей, попавших в 10\% самых цитируемых в мире за последние 5 лет) [19; 21].

Global World Communicator учитывает академическое ранжирование (численность студентов и научно-педагогического состава, количество образовательных программ, научно-исследовательская работа, награды и руководство университета); доступность информации на сайте университета (описание образовательной ор-

$[18 ; 20]$.

Также очень значимым для развития высшего образования в России является проект 5-100, в котором обозначены ключевые показатели: нарастить исследовательский потенциал; привести состав и качество образовательных программ и интеллектуальных продуктов к мировому уровню; интегрировать собственные инновации в профессиональное обучение, развивать общее и дополнительное образование, популяризировать науку среди детей и молодёжи, стимулировать их на творческую деятельность; иметь в штате не менее 10 \% иностранных преподавателей и привлечь не менее 15 \% иностранных студентов. Общей задачей для всех вузов является стремление к повышению индекса цитирования научных статей своих сотрудников [2; 4; 9].

В данной работе мы проанализировали наиболее значимые тренды для высшего образования, индикаторы показателей эффективности работы университетов по наиболее значимым международным рейтингам и сформировали компетентностную модель университета, соответствующую современным вызовам и трендам.

Материалы и методы исследования

Анализируя множество глобальных и развивающихся трендов можно выделить основные, которые являются наиболее весомыми по влиянию на работу образовательных организаций. Первым трендом является глобализация, которая оставляет четкий след в образовании - формируется отдельная группа образовательных организаций, которые являются лидерами в предоставлении образовательных услуг, реализуя программы с международной аккредитацией на нескольких языках $[19 ; 20 ; 21]$.

Вторым трендом, который необходимо отметить является ускорение темпа социального развития, которое в свою очередь приводит к формированию существенного разрыва между общественным бытием и уровнем общественного сознания.

Важным трендом является расширение сетевого пространства, которое приводит к необходимости реализовывать образовательные программы с помощью открытых образовательных платформ и активно использовать для общения с обучающимися социальные сети.

Тренд универсализации миграционных потоков приводит к значительному переформатированию контингента обучающихся в образовательных организациях, что влечет существенные изменения в организации и содержании образовательного процесса [1; 2]. 
Развивающимся и очень перспективным трендом является виртуализация и дополнение реальности. Уже на данный момент этот тренд активно используется в образовательном процессе ведущих университетов, проводятся лабораторные и практические занятия с использованием виртуальной реальности, особенно эффективно его используют в преподавании ITтехнологий [16; 17].

Глобальная конкуренция является тем трендом, который приводит к значительному уменьшению количества образовательных организаций, реализующих программы высшего образования. Благодаря глобальной конкуренции большие вузы поглощают более мелкие и более слабые, в итоге формируются современные образовательные кластеры - конкурентоспособные, владеющие современными технологиями, уникальным материально-техническим и кадровым потенциалом [1; 7].

Следующим трендом является старение населения, что вслед за собой ведет к изменению соотношений между образовательными программами высшего образования. Еще 10 лет назад образовательные программы магистратуры составляли менее 10\% в высшем образовании, на данный момент большинство вузов реализует около 30\% магистерских программ от общего объема образовательных программ. Это указывает на необходимость повышения уровня образования [3-6].

Быстрое развитие технологий требует соответствующего материально-технического и кадрового обеспечения, что также значительно повышает конкуренцию среди образовательных организаций.

Одними из ключевых трендов также являются - снижение уровня здоровья обучающихся и увеличение количества обучающихся с ограниченными возможностями здоровья. Данные тренды требуют создания здоровьеформирующей среды и обеспечения техническими и кадровыми условиями инклюзивного образовательного процесса [10].

Bсе вышеперечисленные факты требуют существенных изменений в системе оценки качества образования в образовательных организациях, что и формирует актуальность разработки стратегии повышения качества образования в современной образовательной организации.

Цель работы - определение критериев эффективности и повышение качества образования в образовательных организациях высшего образования.

\section{Задачи исследования:}

1. Проанализировать глобальные и развивающиеся тренды, имеющие наибольшее влияние на систему образования.

2. Сформировать критерии оценки эффективности работы образовательных организаций.
Результаты исследования

По определению Константинова Г.Н. (2009): «Стратегия - это понимание места и роли компании в будущем потоке событий, позволяющее сформировать интегрированный набор действий, направленный на создание устойчивых конкурентных преимуществ» [7]. Исходя из данного определения для формирования эффективной стратегии повышения качества образования необходимо сформулировать критерии оценки качества образования, которые и будут являться конкурентными преимуществами.

Для формирования перечня критериев качества образования следует обратить внимание на потребительские тренды, которые возникли в России и за рубежом. Основными таковыми трендами являются: безопасность потребления товаров и услуг, сознательность потребления, экологичность потребления и интернетизация потребления [3].

На результативность деятельности вузов оказывают влияние внешние и внутренние факторы. К внешним относятся нормативно-правовые условия ведения образовательной деятельности, климатические и социально-экономические условия региона, конкуренция на образовательном рынке $[14,17,18]$. Внутренние факторы регулируются вузами. К ним относятся стратегические ориентиры в отношении образовательных услуг, имеющиеся у вуза ресурсы и компетенции, характеристики предлагаемых образовательных услуг и стратегии их продвижения [11; 13; 16].

На основании результатов опубликованных научных работ по теме исследования в этой области деятельности и доступной информации были отобраны восемь внутренних факторов [8; 9].

1. Диверсификация образовательных программ вуза. Расширение спектра предлагаемых вузом образовательных услуг повышает вероятность увеличения численности студентов и продления срока их пребывания в статусе потребителей услуг вуза [18].

2. Реализация программ двух дипломов. Международные программы двух дипломов пользуются повышенным спросом у абитуриентов, поскольку дают учащимся возможность в рамках стандартного срока реализации образовательной программы получить опыт обучения и два полноценных диплома об образовании [8; 9].

3. Реализация программ транснационального образования. Вузы - лидеры образовательного рынка активно реализуют программы транснационального образования.

4. Сетевое партнерство с иностранными вузами. Сотрудничество вузов разных стран может предусматривать взаимную поддержку в рекрутинге иностранных сту- 
дентов и продвижении бренда вуза за рубежом [18]. Индикатор: число международных сетей университетов, в которых вуз является партнером.

5. Среднегодовая стоимость образовательных услуг. Индикатор: среднегодовой доход вуза от обучения одного иностранного учащегося.

6. Коммерциализация образовательных услуг для иностранных учащихся. Индикатор: доля иностранных студентов, обучающихся на коммерческой основе.

7. Представленность информации о вузе и его образовательных программах в Интернете. Индикатор: позиция вуза в рейтинге Webometrics.

8. Селективность вуза. Индикатор: средний проходной балл студентов вуза.

Основываясь на описанных факторах и современных трендах, мы сформировали критерии эффективности образовательного процесса, которые основываются на трех основных компонентах: ключевых компетенциях университета, компетенциях преподавателей университета и компетенциях выпускника университета (см. Табл.) [6].

Таблица

\section{Ключевые компетенции}

\begin{tabular}{|c|c|c|}
\hline \multicolumn{3}{|c|}{ Ключевые компетенции } \\
\hline Университетов & Преподавателей & Студентов \\
\hline $\begin{array}{l}\text { Материально-техническое обе- } \\
\text { спечение }\end{array}$ & Научить учится & $\begin{array}{c}\text { Практическое применение полу- } \\
\text { ченных навыков }\end{array}$ \\
\hline Кадровое обеспечение & $\begin{array}{c}\text { Умение использовать материаль- } \\
\text { но-техническое обеспечение и } \\
\text { ІТ-технологии }\end{array}$ & $\begin{array}{c}\text { Владение IT и современными } \\
\text { технологиями }\end{array}$ \\
\hline Качество образовательных услуг & Проектная деятельность & Социальная компетентность \\
\hline Объем дополнительных услуг & $\begin{array}{c}\text { Научно-исследовательская дея- } \\
\text { тельность }\end{array}$ & Управление собой \\
\hline $\begin{array}{c}\text { Уровень ведения научно-исследо- } \\
\text { вательской работы }\end{array}$ & Организационная деятельность & Мышление \\
\hline $\begin{array}{c}\text { Практическая применимость ком- } \\
\text { петенций выпускников }\end{array}$ & \multirow{3}{*}{ Методическая деятельность } & Обучаемость \\
\hline $\begin{array}{c}\text { Здоровьеформирующая среда и } \\
\text { инклюзивное образование }\end{array}$ & & \multirow{2}{*}{$\begin{array}{c}\text { Здоровьеформирующая компе- } \\
\text { тенция }\end{array}$} \\
\hline Проектная деятельность & & \\
\hline
\end{tabular}

Проанализировав ключевые компетенции университетов в призме воздействия глобальных и развивающихся трендов были выбраны следующие критерии:

1. Материально-техническое обеспечение. Для повышения качества образования необходимо учитывать воздействие следующих трендов: расширение сетевого пространства, виртуализация и дополнение реальности, миграционные потоки, быстрое развитие технологий, необходимость формирования здоровьеформирующей среды и базы для инклюзивного образования.

2. Кадровое обеспечение. Данный пункт напрямую связан с предыдущим, поскольку кадры, работающие в данной системе должны владеть компетенциями использования современного материальнотехнического обеспечения. Кроме того, преподаватель должен владеть интерактивными технологиями, технологиями проектного обучения, а также быть одновременно практиком и ученым.
3. Качество образовательных услуг. Четкого инструментария для проверки данной компетенции нет, но существуют определенные механизмы, которые позволяют оценить его в свете глобальных и развивающихся трендов. В данном случае в первую очередь необходимо учитывать потребительские тренды, как тех потребителей, которые получают образовательную услугу, так и потребителей-работодателей. Образовательную услугу можно считать качественной только в том случае, если она удовлетворяет потребности работодателей. Для того чтобы актуализировать образовательную услугу необходимо к разработке образовательной программы привлекать работодателей, которые могут четко указать какими компетенциями должны владеть выпускники определенной программы. После формирования компетентностной части образовательной программы согласовывается содержательная часть, базирующаяся на необходимых компетенциях. 
4. Объем дополнительных услуг предоставляемых образовательной организацией. Для повышения качества образования образовательная организация на базе маркетинговых исследований и потребительских трендов должна сформировать кейс дополнительных услуг, который включает: актуальные программы повышения квалификации и профессиональной переподготовки, а также набор курсов, пользующийся спросом у потребителя на данный момент.

5. Уровень ведения научно-исследовательской работы в университете. В данном аспекте значительный вес имеет материально-техническое и кадровое обеспечение учебного процесса, но компетенция организации научно-исследовательской работы с обучающимися также имеет существенное значение. Мониторинг данного критерия не является проблематичным: учитывается количество и уровень публикаций, обучающихся и преподавателей, количество и качество полученных и выполненных грантов являются основными компонентами.

6. Практическая применимость компетенций выпускников университета контролируется работодателями. Наиболее рациональным критерием оценки является трудоустройство выпускников по профилю подготовки.

7. Здоровьеформирующая среда и инклюзивное образование. Данный компонент обусловлен тенденцией к всеобщему снижению уровня здоровья. Для эффективного обучения должна быть сформирована среда, в которой уровень здоровья будет не только сохранен, но и повышен, также должна быть сформирована доступная среда.

8. Проектная деятельность - данный компонент по мнению ведущих ученых имеет очень большой вес в формировании профессионально необходимых компетенций, большинство ведущих вузов широко используют проектный тип обучения.

Для оценки эффективности работы преподавательского состава среди всех компетенций выделим несколько групп наиболее необходимых:

1. Компетенция «Научить учится». Данная компетенция показывает насколько преподаватель умеет стимулировать обучающихся к самостоятельному обучению, нахождению информации, ее обработке, усвоению и практическому использованию.

2. Компетенция "Умение использовать материально-техническое обеспечение и ITтехнологии». Данная компетенция показывает уровень владения преподавателя техническими средствами обучения и его возможности использования технологий в научно-исследовательской деятельности.

3. Компетенция «Проектная деятельность» показывает уровень владения преподавателем проектной деятельностью, а также его умение обучить студентов данному виду деятельности.

4. Компетенция «Научно-исследовательская деятельность». Отражается в количестве и качестве опубликованных преподавателем работ, а также работ студентов, опубликованных под его руководством. Важным фактором является наличие грантов и качественное их исполнение.

5. Компетенция «Организационная деятельность» является очень важной, поскольку отражает всю деятельность преподавателя по организации различных научных, методических, воспитательных и иных мероприятий, а также его умение работать со студентами.

6. Компетенция «Методическая деятельность», которая отражает владение преподавателем различными методическими приемами, разработку собственных методик, а также их внедрение, включает написание работ методической направленности.

Одним из заключительных этапов нашего исследования было формирование списка ключевых компетенций выпускников для оценки качества образования:

Компетенция «Практическое применение полученных навыков» оценивается работодателем, основные критерии - трудоустройство, удовлетворенность работодателя сформированными компетенциями и практическими навыками.

Компетенция «Владение IT и современными технологиями» современность требует глубокого владения различными технологиями, лишь в этом случае выпускник может быть конкурентоспособен.

«Социальная компетентность» подразумевает умение слушать, убеждение и аргументация, нетворкинг, ведение переговоров, проведение презентаций, самопрезентация, публичные выступления, командная работа, нацеленность на результат, деловое письмо, сформированность личности и мировоззрения.

«Управление собой» включает управление эмоциями, управление стрессом, управление собственным развитием, планирование и целеполагание, тайм-менеджмент, рефлексию.

«Мышление» подразумевает: системное мышление, креативное мышление, структурное мышление, логическое мышление, поиск и анализ информации, выработку и принятие решений, проектное мышление, тактическое и стратегическое мышление [5; 13].

«Обучаемость» - это возможность выпускника быстро и качественно овладевать новыми компе- 
тенциями, знаниями, умениями и навыками.

«Здоровьеформирующая компетенция» умение следить за своим физическим и психологическим состоянием, улучшать свои физические качества и контролировать состояние здоровья.

Обсуждение результатов

На основе сформированного подбора ключевых компетенций университета, ключевых компетенций преподавательского состава и ключевых компетенций выпускника создается план развития конкретной организации, с целью достижения этих компетенций. Данные компетенции являются тем самым конкурентным преимуществом, с помощью которого организация получает определенные преференции перед конкурентами. Основой повышения качества образования в современной образовательной организации является достижение высокого уровня необходимых ключевых компетенций и соответствие показателям мировых рейтингов качества образования.

Заключение

В современном, активно меняющемся и трансформирующемся мире высшее образование попадает под влияние разнообразных трендов и получает множество вызовов. В своей работе мы попытались уесть все основные тенденции, которые будут влиять на развитие высшего образования в России и построили компетентностную модель ключевых компетенций университета, преподавателя и студента, которые позволят конкурировать в современном мире.

ЛИТЕРАТУРА

1. Баталов Э. Современные глобальные тренды и новое сознание / 2012, Том 10, № 1(28). [Электронный peсуpc]. URL: http://www.intertrends.ru/twenty-eight/02.htm (дата обращения: 27.09.2018)

2. Глобальные тренды и перспективы научно-технологического развития Российской Федерации: краткие тезисы : докл. к XVIII Апр. междунар. науч. конф. по проблемам развития экономики и общества, Москва, 1114 апр. 2017 г. / Л.М. Гохберг, А.В. Соколов, А.А. Чулок и др. ; Нац. исслед. ун-т «Высшая школа экономики». М. : Изд. дом Высшей школы экономики, 2017. 39 с.

3. Демидов А. Глобальные тренды и российский потребитель 2017. По результатам международного исследования «GfK Consumer Life». M.: GfK Consumer Life, 2017. 20 c.

4. Екшикеев Т.К. Развитие конкурентного потенциала вуза на рынке образовательных услуг // Проблемы современной экономики. 2009. № 2 (30). [Электронный ресурc]. URL: http://www.m-economy.ru/art. php?nArtld=257 (дата обращения: 27.09.2018)

5. Ивонина А.И. Современные направления теоретических и методических разработок в области управления: роль soft skills $и$ hard skills в профессиональном и карьерном развитии сотрудников / А.И. Ивонина, О.Л. Чуланова, Ю.М. Давлетшина // Интернет-журнал «НАУКОВЕДЕНИЕ». 2017. Том 9, № 1. [Электронный ресурс]. URL: http://naukovedenie.ru/PDF/90EVN117.pdf (дата обращения: 27.09.2018)

6. Колганова Т.А. Стратегии повышения качества высшего профессионального образования в России // Качество современного образования: опыт, тенденции развития : сб. мат. науч.-практ. конф. с междунар. уч. Саратов, 18 февраля 2016 г. Часть 2 / под общ. ред. И.М. Ильковской. Саратов : ГАУ ДПО «СОИРО», 2016. C. 12-16.

7. Константинов Г.Н. Стратегический менеджмент. Концепции : учебное пособие для слушателей программы MBA, обучающихся по специальностям «Общий и стратегический менеджмент» и «Финансы» Гос. ун-т ВШЭ. М.: Бизнес Элайнмент, 2009. 239 с.

8. Меликян А.В. Внутренние факторы результативности экспорта образования в российских вузах // Вопросы образования - Educational Studies Moscow. 2018. № 3. pp. 146-179.

9. Меликян А.В. Основные характеристики международных сетей университетов // Вопросы образования Educational Studies Moscow. 2014. № 3. С.100-117.

10. Орехов С.А. Инновационные стратегии развития как механизм обеспечения конкурентоспособности образовательного учреждения. Монография / С.А. Орехов, Н.И. Решетько. М.: МЭСИ, 2013. С. 3 - 29.

11. Прахов И.А. Детерминанты ожидаемой отдачи от высшего образования в Москве // Вопросы образования - Educational Studies Moscow. 2017. № 1. C.25-57.

12. Рейтинг лучших университетов мира по версии Times higher education [Электронный pecypc]. URL: http:// gtmarket.ru/ratings/the-world-university-rankings/info (дата обращения: 27.09.2018)

13. Шипилов В. Перечень навыков soft-skills и способы их развития [Электронный ресурc]. URL: http://www.cfin. ru/management/people/dev_val/softskills.shtml (дата обращения: 27.09.2018)

14. Штейн Е.И. Оценка эффективности подготовки вузами квалифицированных кадров с использованием компетентностного подхода // Интернет-журнал «НАУКОВЕДЕНИЕ». 2015. Выпуск 4 (23), Июль-август. С. 1-10.

15. Academic ranking of world universities [Электронный ресурc]. URL: http://www.shanghairanking.com/ARWUMethodology-2018.html (дата обращения: 27.09.2018)

16. Chirikov I. How Global Competition is Changing Universities: Three Theoretical Perspectives // Research \& Occasional Paper Series: Center for Studies in Higher Education. 2016. no. 5.16. pp. 1-7.

17. Dimitrova-Galaczi E. Interactional competence across proficiency levels. Paper presented at the Language Testing Research Colloquium, April 2010, Cambridge.

18. Mazzarol T.W. Critical Success Factors for International Education Marketing // International Journal of Educational Management. 1998. Vol.12. No 4. P. 163-175. 
19. Stensaker B. Translating Globalization into Practice: University Networks - Towards a New Stratification of Higher Education? // P. Axelrod, R. D. Trilokrekar, T. Shanahan, R. Wellen (eds) Making Policy in Turbulent Times. Challenges and Prospects for Higher Education. Montreal, QC; Kingston, ON: McGill-Queen's University. 2013. P.249-268.

20. QS World universities rankings: methodology [Электронный ресурc]. URL: https://www.topuniversities.com/qsworld-university-rankings/methodology (дата обращения: 27.09.2018)

21. World University Rankings 2018 methodology [Электронный ресурc]. URL: https://www.timeshighereducation. com/world-university-rankings/2018/world-ranking\#!/page/0/length/25/sort_by/rank/sort_order/asc/cols/stats (дата обращения: 27.09.2018).

REFERENCES

1. Batalov E. Modern Global Trends and New Consciousness . 2012, Vol. 10, No. 1 (28). [Electronic resource]. Available at: http://www.intertrends.ru/twenty-eight/02.htm (accessed 27 September 2018) (in Russian)

2. Global Trends and Prospects of the Scientific and Technological Development of the Russian Federation: A Brief Thesis: Report. to XVIII Apr. International scientific conf. on problems of economic and social development, Moscow, April 11-14. 2017 / L.M. Gokhberg, A.V. Sokolov, A.A. Chulok and others; Nat researches University "Higher School of Economics". Moscow, Ed. House of the Higher School of Economics, 2017. 39 p. (in Russian)

3. Demidov A. Global Trends and Russian Consumer 2017. According to the results of the international research "GfK Consumer Life". Moscow, GfK Consumer Life Publ., 2017. 20 p. (in Russian)

4. Ekshikeev T.K. Development of the competitive potential of the university in the educational market. Problems of the modern economy. 2009. no. 2 (30). [Electronic resource]. Available at: http://www.m-economy.ru/art. php?nArtld=257 (accessed 27 September 2018) (in Russian)

5. Ivonina A.I. Modern directions of theoretical and methodological developments in the field of management: the role of soft skills and hard skills in the professional and career development of employees / A.I. Ivonina, O.L. Chulanova, Yu.M. Davletshina. Internet magazine "SCIENCE". 2017. Vol. 9, No. 1. [Electronic resource]. URL: http:// naukovedenie.ru/PDF/90EVN117.pdf (accessed 27 September 2018) (in Russian)

6. Kolganova T.A. Strategies for improving the quality of higher professional education in Russia. Quality of modern education: experience, development trends: Coll. mat. scientific-practical conf. from Intern. uch. Saratov, February 18, 2016. Part 2. Saratov: GAU DPO "SOIRO" Publ., 2016. pp. 12-16. (in Russian)

7. Konstantinov G.N. Strategic management. Concepts: a manual for students of the MBA program, students in the specialties "General and strategic management" and "Finance" State. Univ - HSE. Moscow, Business Element Publ., 2009. 239 p. (in Russian)

8. Melikyan A.V. Internal factors of the effectiveness of the export of education in Russian universities. Voprosy obrazovania - Educational Studies Moscow. 2018. no. 3. pp. 146-179. (in Russian)

9. Melikyan A.V. The main characteristics of international university networks. Voprosy obrazovania - Educational Studies Moscow. 2014. no. 3. C.100-117. (in Russian)

10. Orekhov S.A. Innovative development strategies as a mechanism for ensuring the competitiveness of an educational institution. Monograph / S.A. Orekhov, N.I. Reshetko. Moscow, MESI Publ., 2013. pp. 3 - 29. (in Russian)

11. Prakhov I.A. Determinants of the expected return from higher education in Moscow. Voprosy obrazovania Educational Studies Moscow. 2017. no. 1. pp. 25-57. (in Russian)

12. Ranking of the best universities in the world according to Times higher education [Electronic resource]. Available at http://gtmarket.ru/ratings/the-world-university-rankings/info (accessed 27 September 2018) (in Russian)

13. Shipilov V. The list of soft-skills and ways of their development [Electronic resource]. Available at: http://www.cfin. $\mathrm{ru} / \mathrm{management/people/dev \_ val/softskills.shtml} \mathrm{(accessed} 27$ September 2018) (in Russian)

14. Stein E.I. Evaluation of the effectiveness of training of qualified personnel by universities using the competencebased approach. Internet magazine "SCIENCE". 2015. Issue 4 (23), July - August. pp. 1-10. (in Russian)

15. Academic ranking of world universities [Electronic resource]. URL: http://www.shanghairanking.com/ARWUMethodology-2018.html (accessed 27 September 2018)

16. Chirikov I. How Global Competition is a Changing Universities: Three Theoretical Perspectives. Higher Education. 2016. no. 5.16. pp. 1-7.

17. Dimitrova-Galaczi E. Interactional competence across proficiency levels. Paper presented at the Language Testing Research Colloquium, April 2010, Cambridge.

18. Mazzarol T.W. Critical Success Factors for International Education Marketing. International Journal of Educational Management. 1998. Vol.12. No 4. pp. 163-175.

19. Stensaker B. Translating Globalization into Practice: University Networks? // P. Axelrod, R. D. Trilokrekar, T. Shanahan, R. Wellen (eds) Making Policy in Turbulent Times. Challenges and Prospects for Higher Education. Montreal, QC; Kingston, ON: McGill-Queen's University. 2013. pp. 249-268.

20. QS World groups rankings: methodology [Electronic resource]. URL: https://www.topuniversities.com/qs-worlduniversity-rankings/methodology (accessed 27 September 2018)

21. World University Rankings 2018 methodology [Electronic resource]. URL: https://www.timeshighereducation. com/world-university-rankings/2018/world-ranking\#!/page/0/length/25/sort_by/rank/sort_order/asc/cols/stats (accessed 27 September 2018) 


\section{Информация об авторах \\ Воронин Денис Михайлович (Россия, Москва)}

Кандидат наук по физическому воспитанию и спорту, доцент

Декан факультета биологии, химии и экологии Государственный гуманитарно-технологический университет

E-mail: doctordennis@yandex.ru

Мишина Ольга Степановна

(Россия, г. Орехово-Зуево)

Кандидат сельскохозяйственных наук, директор Ресурсного центра педагогического образования Московской области Государственный гуманитарно-технологический университет

E-mail: olyamishin@yandex.ru

\section{Завальцева Ольга Александровна}

(Россия, г. Орехово-Зуево)

Кандидат биологических наук, доцент, доцент кафедры биологии и экологии

Государственный гуманитарно-технологический университет

E-mail: z.olga1979@mail.ru

\section{Ссылка для цитированиягост}

Воронин Д. М., Мишина О. С., Завальцева О. А. Критерии эффективности современной образовательной организации как основа оценки и повышения качества образования // Перспективы науки и образования. 2018. № 5 (35). С. 18-25. doi: $10.32744 /$ pse.2018.5.2

\section{Information about the authors}

Denis M. Voronin

(Russia Moscow)

$\mathrm{PhD}$ in Physical Education and sport Associate professor

Dean of the Faculty of Biology, Chemistry and Ecology

State Humanitarian University of Technology

E-mail: doctordennis@yandex.ru

Olga S. Mishina

(Russia, Orekhovo-Zuyevo)

$\mathrm{PhD}$ in Agricultural Sciences,

Director of the Resource Center for Teacher Education of the Moscow Region

State Humanitarian University of Technology

E-mail: olyamishin@yandex.ru

\section{Olga A. Zavaltseva}

(Russia, Orekhovo-Zuyevo)

$\mathrm{PhD}$ in Biological Sciences, Associate Professor,

Associate Professor of the Department of Biology and Ecology

State Humanitarian University of Technology E-mail: z.olga1979@mail.ru

\section{For Reference ${ }^{\mathrm{APA}}$}

Voronin, D. M., Mishina, O. S., \& Zavaltseva, O. A. (2018). Modern educational organisation effectiveness criteria as education quality evaluation and quality enhancement basics. Perspektivy nauki i obrazovaniaPerspectives of Science and Education, 35 (5), 18-25. doi: 10.32744/pse.2018.5.2. (In Russ., abstr. in Engl.) 